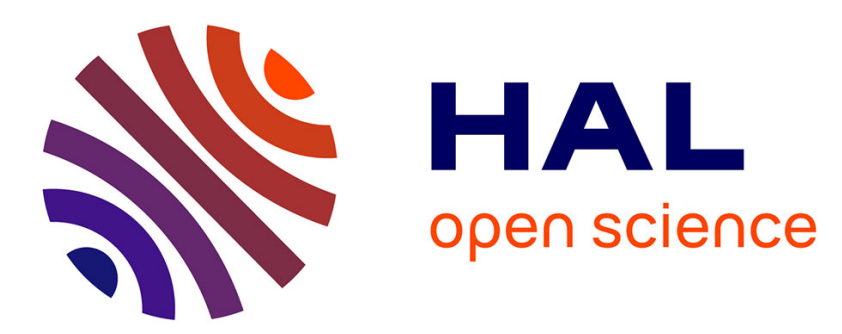

\title{
Replication stress and genome rearrangements: lessons from yeast models
}

\author{
Sarah Lambert, Antony M Carr
}

\section{To cite this version:}

Sarah Lambert, Antony M Carr. Replication stress and genome rearrangements: lessons from yeast models. Current Opinion in Genetics and Development, 2013, 23 (2), pp.132-139. 10.1016/j.gde.2012.11.009 . hal-03008993

\section{HAL Id: hal-03008993 \\ https://hal.science/hal-03008993}

Submitted on 29 Sep 2021

HAL is a multi-disciplinary open access archive for the deposit and dissemination of scientific research documents, whether they are published or not. The documents may come from teaching and research institutions in France or abroad, or from public or private research centers.
L'archive ouverte pluridisciplinaire HAL, est destinée au dépôt et à la diffusion de documents scientifiques de niveau recherche, publiés ou non, émanant des établissements d'enseignement et de recherche français ou étrangers, des laboratoires publics ou privés. 


\title{
Replication stress and genome rearrangements: lessons from yeast models
}

\author{
Sarah Lambert ${ }^{1,2}$ and Antony M. Carr ${ }^{3}$
}

1. Institut Curie, Bat 100, 91405, Orsay, France.

2. Centre national de la recherche scientifique, UMR3348, centre universitaire, Paris Sud XI, 91405, Orsay, France.

3. Genome Damage and Stability Centre, School of Life Sciences, University of Sussex, Brighton, BN1 9RQ, UK.

Correspondance:

e-mail: a.m.carr@sussex.ac.uk. Tel: 01273 678122, Fax: 01273678121 


\begin{abstract}
Replication failures induced by Replication fork barriers (RFBs) or global replication stress generate many of the chromosome rearrangement (CR) observed in human genomic disorders and cancer. RFBs have multiple causes and cells protect themselves from the consequences of RFBs using three general strategies: preventing expression of RFB activity, stabilising the arrested replisome and, in the case of replisome failure, shielding the fork DNA to allow rebuilding of the replisome. Yeast models provide powerful tools to understand the cellular response to RFBs, delineate pathways that suppress genome instability and define mechanisms by which CRs occur when these fail. Recent progress has identified key features underlying RFBs activity and is beginning to uncover the DNA dynamics that bring about genome instability.
\end{abstract}




\section{Introduction}

Replication errors induced by natural replication fork barriers (RFBs) and global replication stress underlie many genome rearrangements at the chromosomal and nucleotide level. RFBs have multiple causes including DNA damage, DNA secondary structure, non-histone protein:DNA interactions, replicationtranscription clashes and the structure of the chromatin itself [1-3]. Each RFB class will perturb both the replisome and associated DNA fork in distinct ways [4]. All RFBs cause replisome and fork "arrest" (see box 1 for definitions). Ideally, these are stabilised ("stalled" fork) by the intra-S phase checkpoint (ISC) and remain competent to resume replication. In other cases, the replisome and fork will "collapse", leaving a variety of DNA structures prone to inappropriate processing [5,6]. Cells protect themselves from the consequences of fork arrest using three strategies: first, specialised pathways attempt to prevent RFB expression, for example by repairing DNA damage or dissociating protein:DNA interactions using specialised helicases [7]. Second, when RFBs are expressed, the intra-S phase checkpoint attempts to maintain the replisome in a replicationcompetent "stalled" conformation [8,9]. There is also evidence that the ISC regulates proteins that may inappropriately process the fork $\left[10^{*}, 11-13\right]$. Finally, if a fork does collapse, the exposed DNA structure is protected and the replisome can be rebuilt to allow restart $\left[14^{* *}, 15,16^{* *}, 17^{*}, 18\right]$.

\section{Replication failures and chromosomal rearrangements}

A low level of mutation maintains natural variation between individuals and allows evolution. However, mutations also cause human disease, including cancer that is typified by elevated genome instability. One class of human diseases, genomic disorders, is characterized by inherited structural DNA changes $[19,20]$. Some of these chromosomal rearrangements (CRs) underlying genomic disorders are instigated by non-allelic homologous recombination (NAHR) during parental meiosis [21]. Alternatively, the CR can originate in mitotic cells as a result of replication failure [22*]. Thus, genomic disorders can provide a snapshot of a single replication-associated outcome that occurred in a single parental mitosis. A variety of CRs are associated with genomic disorders, including reciprocal and non-reciprocal translocations, terminal deletions which can be associated with proximal inverted duplications - plus a variety of single or linked inversions, deletions and duplications [23**-26]. We will not review these in detail, but exemplars are presented, along with potential mechanisms, in box 2 and table 1. 
A phenomenon allowing visualisation of replication errors at the cellular level are fragile sites, first defined as chromosome breaks or gaps observed in the condensed chromosomes of cells previously grown under mild replication stress $[27,28]$. Rare fragile sites are associated with secondary structure-forming satellite repeats. Common fragile sites (CFS) have attracted more attention and are defined as loci with chromosome breaks/gaps in a significant percentage of cells [29]. Recent work has linked CFS to regions where origin density is low $\left[30^{* *}, 31^{* *}, 32^{* *}\right]$. CFS thus replicate late and their expression during mild replication stress (either imposed experimentally or intrinsic) results from incomplete replication when cells enter mitosis [33,34]. Some CFS are proposed to contain difficult to replicate sequences and approximately $50 \%$ contain particularly large genes $(>500 \mathrm{~Kb})$ [35-37]. CFS expression can act as a surrogate marker for local replication problems.

The considerable interest in how replication failure results in genome alterations stems from the desire to understand the aetiology of genomic disorders and the fact that carcinogenesis is driven by genome instability, inactivating tumour suppressors and activating oncogenes. The increased genome instability during carcinogenesis is linked to oncogene-induced proliferation that results in imbalanced replication; e.g. S phase with compromised nucleotide production $\left[38,39^{* *}, 40^{*}\right]$. In addition to CRs, breast cancer cells can exhibit clustered mutations surrounding the break-points of somatic rearrangements (Kataegis) [41*]. In yeasts, chronic replication stress can result in damaged single-stranded DNA, resulting in clustered mutations over 100's of $\mathrm{kb}\left[42^{*}\right]$. Because studies in mammalian cells are complex, the mechanisms underlying genome instability via compromised replication are generally implied from the sequence of breakpoint junctions.

The most toxic DNA lesion is the double strand break (DSB). DSBs are prone to recombination that, if ectopic, results in CRs including translocations, inversions, duplications and deletions (Figure 1) [21,43]. Homologous recombination (HR) also drives loss of heterozygosity in diploid organisms. Single HR events can result in simple CRs [44]. More complex CRs are often proposed to result from the formation of dicentric chromosomes. These are initiated from a single HR event, but generate complex CRs via breakage-fusion-bridge (BFB) cycles that instigate multiple iterative HR events $\left[14^{* *}, 45\right]$.

Many human CRs can thus be modelled as the product of a single DSB. Combined with knowledge from preceding bacterial models and the lack of contrary experimental evidence, this led to the assumption that DSB 
intermediates are common to all replication-induced CRs. Recent evidence challenges this view, suggesting many replication-induced CRs occur without a DSB intermediate and that complex CRs can arise from multiple independent or linked events. The 3D-organisation pattern of DNA replication also helps shape rearrangements in cancers cells [ $\left.46^{*}\right]$. Combining the tools available in yeast models with advances in identifying CRs and their intermediates in mammalian cells provides exciting opportunities to establish and test new models of genome instability.

\section{Yeast models for genome instability}

Intrinsic RFBs (iRFBs) have been identified in yeasts using genome-wide analysis of either DNA polymerase occupancy or the presence of phosphorylated H2A $(\gamma \mathrm{H} 2 \mathrm{~A})$, a DNA damage marker $\left[47^{* *}, 48^{*}\right]$. These defined various iRFB classes, including non-histone protein:DNA interactions and replication-transcription clashes [49,50]. Many iRFBs are strongly expressed only in the absence of Pif1family ancillary helicase, which functions at the replisome to remove potential protein:DNA barriers [51]. Other iRFBs are caused by transcription-associated DNA:RNA hybrids (R-loops) and, more recently, a subset have been associated with transcriptional repression and histone hypo-acetylation $\left[47^{* *}, 52-54\right]$ providing an interesting correspondence with six humans CFS which are hypoacetylated [55]. In both yeast and mammals, inhibition of histone deacetylases relieves iRFBs activity and CFS instability, suggesting that hypo-acetylated chromatin interferes with fork progression $\left[47^{* *}, 55\right]$. In addition to iRFBs, eukaryotes including yeasts, have evolved polar programmed RFBs (pRFBs) to arrest forks travelling in one, but not the opposite, direction [56-58]. The most prevalent $\mathrm{pRFBs}$ lie within the ribosomal DNA repeats, acting to enforce codirectional replication and transcription [59].

Structure-forming sequences acting as RFBs, known as "at risk motifs" (ARMs), include tri-nucleotides repeats, GC rich motifs capable of forming G-quadruplex (G4), inverted repeats that can form hairpins and palindromes that form cruciform structures. All these ARMs can induce replication-dependent genome instability in yeast models for human genome instability [60-63] (Table 1). We do not exhaustively review these, but provide exemplars of recent progress. In yeasts, G-quadruplexes are unstable in the absence of the specialized helicases that presumably prevent fork arrest by unwinding the G4 structure $\left[64^{*}, 65^{*}, 66^{*}\right]$. G4-induced CRs are driven by HR, implying instability results from processing of collapsed forks. Currently, little is known about G4 and CRs in human cells, but G4 DNA has been linked with somatic copy-number alterations [67]. Yeasts 
have also proved excellent models for understanding mechanisms underlying the instability of disease-associated ARMs. Large scale GAA repeat expansion of underpins Friedreich Ataxia [68,69]. In yeast, tracts of $>40$ GAA/TTC repeats impede fork progression when the GAA sequence is on the lagging strand, implicating secondary structure in ssDNA [70]. This results in elevated recombination and CRs [71,72]. The tools available in yeasts have revealed that several replication-dependent mechanisms account for this instability.

\section{Modelling HR restart}

A prevalent feature of replication-associated $\mathrm{CR}$ is recombination. HR proteins can restart collapsed forks implying a direct link. HR fork restart was modelled by generating a telomere-proximal DSB in mitotically arrested budding yeast with homology to an internal region of another chromosome [73,74]. This promoted DNA synthesis from the break to the template chromosomes end $(>100 \mathrm{~Kb})$ using a single replisome [75]. Break induced replication (BIR) requires all essential replication proteins, with the expected exception of those needed for pre-RC assembly [76]. A requirement for an inessential polymerase delta subunit, Pol32, and specific genetic interactions with PCNA alleles nonetheless distinguishes BIR from canonical replication. BIR forks are prone to template exchange and are hyper-mutagenic, displaying increased template switching plus frameshift mutagenesis rates elevated several thousand fold [*77,78].

HR initiate BIR at regions of significant homology, modelling mitotic NAHR in terms of breakpoint junctions. However, many human CRs are defined by microhomology at the junction. It has been proposed that, in the absence of HR, DSBs can induce replication restart via micro-homology [79]. This microhomology-mediated BIR (MMBIR) model, which lacks direct experimental support, presupposes a DSB as a necessary intermediate [80]. An alternative model derives from investigations into the aetiology of segmental duplications (SD) in yeast $\left[81^{*}\right]$. This uncovered two mechanisms: one required HR proteins, Pol32 and was typified by junctions defined by hundreds of bp homology. This was proposed to be equivalent to BIR. The second mechanism, termed microhomology/microsatellite-induced replication (MMIR), occurred in the absence of all known repair pathways, exhibited only a few bp of junction homology but still required Pol32. While exploiting yeast genetics to identify pathways and narrow down mechanism, this study (like many others) suffered from the inability to study physical intermediates due to the rare nature of the events being selected. Thus it remains unclear if a DSB is an intermediate. 
To overcome limitations relating to the inability to identify intermediates between RFB expression and the consequential CRs, several groups introduced protein:DNA barriers into yeast genomes. Ribosomal RFBs are not mutagenic and do not promote HR ([82] and unpublished data). In contrast, exogenous DNA binding repeats, e.g. LacO, are highly unstable when bound by the cognate binding protein and promote replication-dependent DNA bridges between sister nuclei during mitosis reminiscent of structures associated with CFS [83-85]. DSBs were only observed after mitosis has initiated, suggesting segregation of unreplicated DNA. pRFBs derived from fission yeast have also been informative: when placed ectopically at a locus well characterised for its replication dynamics, HR-dependent replication occurs via a DSB-independent mechanism $\left[14^{* *}, 15,16^{* *}\right]$. During the restart event itself, HR could incorrectly target a nearby homologous sequence, generating NAHR-type CRs, where the junction is defined by hundreds of bp of homology. This is reminiscent of BIR, but without the DSB intermediate. However, once replication has restarted at the correct sequence, HR-restarted replication forks are error prone and partial to generating small deletions and insertions with microhomology at the junctions [**86]. These HR-restarted forks are also prone to U-turn at small inverted repeats, generating acentric and dicentric chromosomes (unpublished data). Thus, like with BIR, replication restarted by HR independently of a DSB is error prone.

Inaccurate replication subsequent to HR-dependent fork restart provides a potential explanation for $\mathrm{CRs}$ induced by replication failures, mimicking microhomology-mediated changes and showing potential for multiple linked events that define some genomic disorders. Since low dNTP level and DNA polymerase inhibition causes non-recurrent copy number variations (CNVs) mediated by either NAHR and micro-homology in human cells, it is possible that both HR-dependent fork restart (i.e. NAHR) and subsequent progression of the HR-dependent faulty fork (microhomology) both similarly contribute to CRs during replication stress $\left[87-89^{*}\right]$. Interfering with fork elongation also results in epigenetic instability by affecting histone recycling and the inheritance of histone marks $\left[90^{*}\right]$. This results in changes in gene expression $\left[84,91^{*}\right]$. Thus, as with replication-induced CRs, an attractive untested possibility is that HR-dependent forks also contribute to replication-induced epigenetic instability.

\section{Conclusion/perspective}

Causes of RFBs and global replication stress are many and varied. Each has the potential to affect the replisome differently. Dependent on cellular responses, the distinct RFBs will have discrete consequences for the fork, influencing its potential to engage in inappropriate metabolism. To ultimately understand the 
links between replication and CRs, it is necessary to examine many alternative experimental systems. Yeasts offer the tools to shed mechanistic insight into how human CR's occur. However, challenges remain: experiments examining stochastic events, while benefiting from the ease of genetic manipulation and rare-event selection, largely suffer from the inability to examine intermediates and require extrapolation from the DNA sequence identified. Introducing RFBs at defined loci allows physical identification of intermediates, significantly increasing the ability to define mechanism, but at the expense of either limiting the type and, potentially, the generality of the RFB examined (e.g. pRFBs) or presupposing a specific intermediate (e.g. BIR). Thus, progress will best be made by combining data from multiple systems, remaining open-minded as to the intermediates involved and establishing robust correlations both within the yeast models and between yeasts and mammalian systems.

\section{Acknowledgement}

We sincerely apologise to our colleagues whose contributions are not cited due to space constraints. SL is supported by Agence Nationale Recherche grants ANR-Piribio09-44854 and ANRJCJC10-1203 01 and la Ligue contre le cancer (comité Essonne). AMC acknowledges Medical Research Council grant G1100074 and Association for International Cancer Research grant 12-1118.

\section{Bibliography}

1. Mirkin EV, Mirkin SM: Replication fork stalling at natural impediments. Microbiol Mol Biol Rev 2007, 71:13-35.

2. Deshpande AM, Newlon CS: DNA replication fork pause sites dependent on transcription. Science 1996, 272:1030-1033.

3. Lambert S, Carr AM: Checkpoint responses to replication fork barriers. Biochimie 2005, 87:591-602.

4. Branzei D, Foiani M: Maintaining genome stability at the replication fork. Nat Rev Mol Cell Biol. 2010, 11:208-219.

5. Weinert T, Kaochar S, Jones H, Paek A, Clark AJ: The replication fork's five degrees of freedom, their failure and genome rearrangements. Curr Opin Cell Biol 2009, 21:778-784.

6. Sogo JM, Lopes M, Foiani M: Fork reversal and ssDNA accumulation at stalled replication forks owing to checkpoint defects. Science 2002, 297:599-602.

7. Ivessa AS, Lenzmeier BA, Bessler JB, Goudsouzian LK, Schnakenberg SL, Zakian VA: The Saccharomyces cerevisiae helicase Rrm3p facilitates 
replication past nonhistone protein-DNA complexes. Mol Cell 2003, 12:1525-1536.

8. De Piccoli G, Katou Y, Itoh T, Nakato R, Shirahige K, Labib K: Replisome stability at defective DNA replication forks is independent of $s$ phase checkpoint kinases. Mol Cell 2012, 45:696-704.

9. Katou Y, Kanoh Y, Bando M, Noguchi H, Tanaka H, Ashikari T, Sugimoto K, Shirahige K: S-phase checkpoint proteins Tof1 and Mrc1 form a stable replication-pausing complex. Nature 2003, 424:1078-1083.

*10. Hu J, Sun L, Shen F, Chen Y, Hua Y, Liu Y, Zhang M, Hu Y, Wang Q, Xu W, et al.: The intra-S phase checkpoint targets Dna2 to prevent stalled replication forks from reversing. Cell 2012, 149:1221-1232.

Dna2 is a direct substrate for the checkpoint kinase Cds1 Chk2. The phosphorylated form of Dna2 cleaves regressed nascent strands to prevent fork regression.

11. Cotta-Ramusino C, Fachinetti D, Lucca C, Doksani Y, Lopes M, Sogo J, Foiani M: Exo1 processes stalled replication forks and counteracts fork reversal in checkpoint-defective cells. Mol Cell 2005, 17:153-159.

12. Froget $B$, Blaisonneau J, Lambert $S$, Baldacci G: Cleavage of stalled forks by fission yeast Mus81/Eme1 in absence of DNA replication checkpoint. Mol Biol Cell 2008, 19:445-456.

13. Lopes M, Cotta-Ramusino C, Pellicioli A, Liberi G, Plevani P, Muzi-Falconi M, Newlon CS, Foiani M: The DNA replication checkpoint response stabilizes stalled replication forks. Nature 2001, 412:557-561.

**14. Mizuno K, Lambert S, Baldacci G, Murray JM, Carr AM: Nearby inverted repeats fuse to generate acentric and dicentric palindromic chromosomes by a replication template exchange mechanism. Genes Dev 2009, 23:2876-2886.

Restart of collapsed forks by HR results in homology-driven template switches of nascent strands, leading to CRs. Visualising replication and recombination intermediates by 2-dimensional gel electrophoresis demonstrated that restart of collapsed forks and associated CR are not initiated by a DSB.

15. Lambert S, Watson A, Sheedy DM, Martin B, Carr AM: Gross chromosomal rearrangements and elevated recombination at an inducible site-specific replication fork barrier. Cell 2005, 121:689-702.

**16. Lambert S, Mizuno K, Blaisonneau J, Martineau S, Chanet R, Fréon K, Murray JM, Carr AM, Baldacci G: Homologous recombination restarts blocked replication forks at the expense of genome rearrangements by template exchange. Mol cell 2010, 39:346-359.

See annotation to Ref [14] 
*17. Hashimoto Y, Puddu F, Costanzo V: RAD51- and MRE11-dependent reassembly of uncoupled CMG helicase complex at collapsed replication forks. Nat Struct Mol Biol 2011, 19:17-24.

In Xenopus extracts after replication stress, GINS and DNA polymerase epsilon loaded onto DNA in a manner requiring homologous recombination, supporting the view that the ability of homologous recombination to rebuild a replisome during DNA replication is conserved from bacteria to metazoans.

18. Moriel-Carretero M, Aguilera A: A postincision-deficient TFIIH causes replication fork breakage and uncovers alternative Rad51- or Pol32mediated restart mechanisms. Mol Cell 2010, 37:690-701.

19. Lupski JR: Genomic disorders: structural features of the genome can lead to DNA rearrangements and human disease traits. Trends Genet 1998, 14:417-422.

20. Lupski JR: Genomic disorders ten years on. Genome Med 2009, 1:42.

21. Liu P, Carvalho CM, Hastings PJ, Lupski JR: Mechanisms for recurrent and complex human genomic rearrangements. Curr Opin Genet Dev 2012, 22:211-220.

*22. Zhang F, Khajavi M, Connolly AM, Towne CF, Batish SD, Lupski JR: The DNA replication FoSTeS/MMBIR mechanism can generate genomic, genic and exonic complex rearrangements in humans. Nat Genet 2009, 41:849-853.

Analysis of non-recurrent rearrangements in genomic disorders (i.e. PotockiLupski microduplication syndrome and Smith-Magenis microdeletion syndrome) identified complex rearrangements, such as duplication-triplication-deletions, over megabases of the human genome alongside small deletions involving a single genes or exons. Rearrangements observed are consistent with mitotic events and replication-based processes.

*23. Liu P, Erez A, Nagamani SC, Dhar SU, Kolodziejska KE, Dharmadhikari AV, Cooper ML, Wiszniewska J, Zhang F, Withers MA, et al.: Chromosome catastrophes involve replication mechanisms generating complex genomic rearrangements. Cell 2011, 146:889-903.

Chromothripsis refers to abundant genomic rearrangements in one chromosome arm arising from a single catastrophic event. Chromothripsis was first identified in cancer cells. Some CRs characterized in genomic disorders share the features of chromothripis, suggesting that fundamental processes, such as DNA replication, can underpin complex rearrangements in otherwise distinct circumstances.

24. Zuffardi O, Bonaglia M, Ciccone R, Giorda R: Inverted duplications deletions: underdiagnosed rearrangements?? Clin Genet 2009, 75:505-513. 
25. Lee JA, Carvalho CM, Lupski JR: A DNA replication mechanism for generating nonrecurrent rearrangements associated with genomic disorders. Cell 2007, 131:1235-1247.

26. Carvalho CM, Ramocki MB, Pehlivan D, Franco LM, Gonzaga-Jauregui C, Fang P, McCall A, Pivnick EK, Hines-Dowell S, Seaver LH, et al.: Inverted genomic segments and complex triplication rearrangements are mediated by inverted repeats in the human genome. Nat Genet 2011, 43:1074-1081.

27. Durkin SG, Glover TW: Chromosome fragile sites. Annu Rev Genet 2007, 41:169-192.

28. Glover TW, Berger C, Coyle J, Echo B: DNA polymerase alpha inhibition by aphidicolin induces gaps and breaks at common fragile sites in human chromosomes. Hum Genet 1984, 67:136-142.

29. Glover TW, Arlt MF, Casper AM, Durkin SG: Mechanisms of common fragile site instability. Hum Mol Genet 2005, 14 Spec No. 2:R197-205.

**30. Le Tallec B, Dutrillaux B, Lachages AM, Millot GA, Brison O, Debatisse M: Molecular profiling of common fragile sites in human fibroblasts. Nat Struct Mol Biol 2011, 18:1421-1423.

These studies revisit the causes of CFS expression by molecular DNA combing and FISH. CFS have low levels of replication origins. Thus, dormant origins cannot rescue DNA replication in response to middle replication stress. Importantly, the expression of CFS relies on the temporal DNA replication program and is thus cell-type specific. Fork arrest within AT-rich regions were also identified for FRA16C, emphasizing that CFS instability originates from multiple mechanisms.

**31. Ozeri-Galai E, Lebofsky R, Rahat A, Bester AC, Bensimon A, Kerem B:

Failure of origin activation in response to fork stalling leads to chromosomal instability at fragile sites. Mol Cell 2011, 43:122-131.

See annotation to Ref [30]

**32. Letessier A, Millot GA, Koundrioukoff S, Lachages AM, Vogt N, Hansen RS, Malfoy B, Brison O, Debatisse M: Cell-type-specific replication initiation programs set fragility of the FRA3B fragile site. Nature 2011, 470:120-123.

See annotation to Ref [30]

33. Chan KL, Hickson ID: New insights into the formation and resolution of ultra-fine anaphase bridges. Semin Cell Dev Biol 2011, 22:906-912.

34. Chan KL, Palmai-Pallag T, Ying S, Hickson ID: Replication stress induces sister-chromatid bridging at fragile site loci in mitosis. Nat Cell Biol. 2009, 11:753-760. 
35. Zhang $\mathrm{H}$, Freudenreich $\mathrm{CH}$ : An AT-rich sequence in human common fragile site FRA16D causes fork stalling and chromosome breakage in S. cerevisiae. Mol Cell 2007, 27:367-379.

36. Helmrich A, Ballarino M, Tora L: Collisions between replication and transcription complexes cause common fragile site instability at the longest human genes. Mol Cell 2011, 44:966-977.

37. Helmrich A, Stout-Weider K, Hermann K, Schrock E, Heiden T: Common fragile sites are conserved features of human and mouse chromosomes and relate to large active genes. Genome Res 2006, 16:1222-1230.

38. Halazonetis TD, Gorgoulis VG, Bartek J: An oncogene-induced DNA damage model for cancer development. Science 2008, 319:1352-1355.

**39. Bester AC, Roniger M, Oren YS, Im MM, Sarni D, Chaoat M, Bensimon A, Zamir G, Shewach DS, Kerem B: Nucleotide deficiency promotes genomic instability in early stages of cancer development. Cell 2011, 145:435-446.

Extends the oncogene-induced DNA damage model by showing that overexpression of the oncogenic $\mathrm{Rb}$-E2F pathway down regulates nucleotide pools, unbalancing DNA replication. Expression of c-myc rescues these defects ${ }^{*} 40$. Chabosseau P, Buhagiar-Labarchede G, Onclercq-Delic R, Lambert S, Debatisse M, Brison O, Amor-Gueret M: Pyrimidine pool imbalance induced by BLM helicase deficiency contributes to genetic instability in Bloom syndrome. Nat Commun 2011, 2:368.

Bloom syndrome associates increased genome instability with a cancer predisposition. In this disease, cytidine deaminase CDA is down regulated. The resulting unbalanced nucleotide pools lead to replication defects, illustrating the importance of coordinating nucleotide pool with replication.

*41. Nik-Zainal S, Alexandrov LB, Wedge DC, Van Loo P, Greenman CD, Raine $\mathrm{K}$, Jones D, Hinton J, Marshall J, Stebbings LA, et al.: Mutational processes molding the genomes of 21 breast cancers. Cell 2012, 149:979993.

Mathematical models of the mutational landscape of 21 breast cancers revealed regions of clustered bases substitutions, called "kataegis", located at break points of somatic CR. Hypermutations are proposed to result from cytosine deamination within region of ssDNA. Defects in homologous recombination (BRCA1 or BRCA2 deficient cells) may leads to ssDNA accumulation. Strikingly, chronic exposure to DNA-alkylation results in of clustered and strand coordinated mutations in budding yeast (Ref [42]).

*42. Roberts SA, Sterling J, Thompson C, Harris S, Mav D, Shah R, Klimczak LJ, Kryukov GV, Malc E, Mieczkowski PA, et al.: Clustered mutations in 
yeast and in human cancers can arise from damaged long single-strand DNA regions. Mol Cell 2012, 46:424-435.

See annotation to Ref [41]

43. Ou Z, Stankiewicz P, Xia Z, Breman AM, Dawson B, Wiszniewska J, Szafranski $\mathrm{P}$, Cooper ML, Rao M, Shao L, et al.: Observation and prediction of recurrent human translocations mediated by NAHR between nonhomologous chromosomes. Genome Res 2010, 21:33-46.

44. Ruiz JF, Gomez-Gonzalez B, Aguilera A: Chromosomal translocations caused by either pol32-dependent or pol32-independent triparental break-induced replication. Mol Cell Biol 2009, 29:5441-5454.

45. Paek AL, Kaochar S, Jones H, Elezaby A, Shanks L, Weinert T: Fusion of nearby inverted repeats by a replication-based mechanism leads to formation of dicentric and acentric chromosomes that cause genome instability in budding yeast. Genes Dev 2009, 23:2861-2875.

*46. De S, Michor F: DNA replication timing and long-range DNA interactions predict mutational landscapes of cancer genomes. Nat Biotechnol 2011, 29:1103-1108.

The integration of genome-wide analysis of somatic copy number alterations in cancer cells with DNA long range interactions strongly suggests that replication errors (either collapsed forks or DSBs) are mistakenly repaired on the basis of micro-homology within a three-dimensional proximity.

**47. Szilard R, Jacques P, Laramée L, Cheng B, Galicia S, Bataille A, Yeung M, Mendez M, Bergeron M, Robert F, et al.: Systematic identification of fragile sites via genome-wide location analysis of gamma-H2AX. Nat Struct Mol Biol. 2010, 17:299-305.

A systematic map of fragile sites at the genome scale level in budding yeast. Fragile sites previously known as "Rrm3-sensitive" are confirmed. In addition chromosome fragility at repressed genes due to the hypo-acetylated chromatin structure was observed.

*48. Rozenzhak S, Mejia-Ramirez E, Williams JS, Schaffer L, Hammond JA, Head SR, Russell P: Rad3 decorates critical chromosomal domains with gammaH2A to protect genome integrity during S-Phase in fission yeast. PLoS Genet 2010, 6:e1001032.

See annotation to Ref [47]

49. Azvolinsky A, Giresi P, Lieb J, Zakian V: Highly transcribed RNA polymerase II genes are impediments to replication fork progression in Saccharomyces cerevisiae. Mol Cell 2009, 34:722-734.

50. Sabouri N, McDonald KR, Webb CJ, Cristea IM, Zakian VA: DNA replication through hard-to-replicate sites, including both highly transcribed RNA 
Pol II and Pol III genes, requires the S. pombe Pfh1 helicase. Genes Dev 2012, 26:581-593.

51. Azvolinsky A, Dunaway S, Torres JZ, Bessler JB, Zakian VA: The S. cerevisiae Rrm3p DNA helicase moves with the replication fork and affects replication of all yeast chromosomes. Genes Dev 2006, 20:31043116.

52. Aguilera A, Garcia-Muse T: R loops: from transcription byproducts to threats to genome stability. Mol Cell 2012, 46:115-124.

53. Prado F, Aguilera A: Impairment of replication fork progression mediates RNA polII transcription-associated recombination. EMBO J 2005, 24:1267-1276.

54. Gomez-Gonzalez B, Garcia-Rubio M, Bermejo R, Gaillard H, Shirahige K, Marin A, Foiani M, Aguilera A: Genome-wide function of THO/TREX in active genes prevents $\mathbf{R}$-loop-dependent replication obstacles. $E M B O \mathrm{~J}$ 2011, 30:3106-3119.

55. Jiang Y, Lucas I, Young DJ, Davis EM, Karrison T, Rest JS, Le Beau MM: Common fragile sites are characterized by histone hypoacetylation. Hum Mol Genet 2009, 18:4501-4512.

56. Dalgaard JZ, Klar AJ: A DNA replication-arrest site RTS1 regulates imprinting by determining the direction of replication at mat1 in S. pombe. Genes Dev 2001, 15:2060-2068.

57. Kaplan DL, Bastia D: Mechanisms of polar arrest of a replication fork. Mol Microbiol 2009, 72:279-285.

58. Singh S, Sabatinos S, Forsburg S, Bastia D: Regulation of replication termination by Reb1 protein-mediated action at a distance. Cell 2010, 142:868-878.

59. Tsang E, Carr A: Replication fork arrest, recombination and the maintenance of ribosomal DNA stability. DNA Repair (Amst) 2008, 7:1613-1623.

60. Lobachev KS, Rattray A, Narayanan V: Hairpin- and cruciform-mediated chromosome breakage: causes and consequences in eukaryotic cells. Front Biosci 2007, 12:4208-4220.

61. Voineagu I, Narayanan V, Lobachev KS, Mirkin SM: Replication stalling at unstable inverted repeats: interplay between DNA hairpins and fork stabilizing proteins. Proc Natl Acad Sci U S A 2008, 105:9936-9941.

62. Bacolla A, Wojciechowska M, Kosmider B, Larson JE, Wells RD: The involvement of non-B DNA structures in gross chromosomal rearrangements. DNA Repair (Amst) 2006, 5:1161-1170.

63. Zhao J, Bacolla A, Wang G, Vasquez KM: Non-B DNA structure-induced genetic instability and evolution. Cell Mol Life Sci 2010, 67:43-62.

Lambert and Carr: page 14 
*64. Ribeyre C, Lopes J, Boule JB, Piazza A, Guedin A, Zakian VA, Mergny JL, Nicolas A: The yeast Pif1 helicase prevents genomic instability caused by G-quadruplex-forming CEB1 sequences in vivo. PLoS Genet 2009, 5:e1000475.

Replication fork passage across G-quadruplex requires the helicase Pif1. When G-quadruplex are not resolved by Pif1, forks arrest and become recombinogenic, triggering genome instability. The data illustrate two strategies for maintaining genome stability in face of iRFBs: a specialized helicase avoids iRFB expression and fork restart mechanisms (HR) complete replication, but at the expense of genome stability.

*65. Paeschke K, Capra JA, Zakian VA: DNA replication through G-quadruplex motifs is promoted by the Saccharomyces cerevisiae Pif1 DNA helicase. Cell 2011, 145:678-691.

See annotation to Ref [64]

*66. Lopes J, Piazza A, Bermejo R, Kriegsman B, Colosio A, Teulade-Fichou MP, Foiani $\mathrm{M}$, Nicolas A: G-quadruplex-induced instability during leadingstrand replication. EMBO J 2011, 30:4033-4046.

See annotation to Ref [64]

67. De S, Michor F: DNA secondary structures and epigenetic determinants of cancer genome evolution. Nat Struct Mol Biol 2011, 18:950-955.

68. McMurray CT: Mechanisms of trinucleotide repeat instability during human development. Nat Rev Genet 2010, 11:786-799.

69. Mirkin SM: DNA structures, repeat expansions and human hereditary disorders. Curr Opin Struct Biol 2006, 16:351-358.

70. Kim HM, Narayanan V, Mieczkowski PA, Petes TD, Krasilnikova MM, Mirkin SM, Lobachev KS: Chromosome fragility at GAA tracts in yeast depends on repeat orientation and requires mismatch repair. $E M B O J$ 2008, 27:2896-2906.

71. Krasilnikova MM, Mirkin SM: Replication stalling at Friedreich's ataxia (GAA)n repeats in vivo. Mol Cell Biol 2004, 24:2286-2295.

72. Shishkin AA, Voineagu I, Matera R, Cherng N, Chernet BT, Krasilnikova MM, Narayanan V, Lobachev KS, Mirkin SM: Large-scale expansions of Friedreich's ataxia GAA repeats in yeast. Mol Cell 2009, 35:82-92.

73. Bosco G, Haber JE: Chromosome break-induced DNA replication leads to nonreciprocal translocations and telomere capture. Genetics 1998, 150:1037-1047.

74. Kraus E, Leung WY, Haber JE: Break-induced replication: a review and an example in budding yeast. Proc Natl Acad Sci U S A 2001, 98:8255-8262. 
75. Lydeard JR, Jain S, Yamaguchi M, Haber JE: Break-induced replication and telomerase-independent telomere maintenance require Pol32. Nature 2007, 448:820-823.

76. Lydeard JR, Lipkin-Moore Z, Sheu YJ, Stillman B, Burgers PM, Haber JE: Break-induced replication requires all essential DNA replication factors except those specific for pre-RC assembly. Genes Dev 2010, 24:1133-1144.

**77. Deem A, Keszthelyi A, Blackgrove T, Vayl A, Coffey B, Mathur R, Chabes A, Malkova A: Break-induced replication is highly inaccurate. PLoS Biol 2011, 9:e1000594.

Origin-independent replication forks built during DSB repair by recombination (BIR) are highly error-prone over of hundreds of kilobases. BIR-induced mutagenesis is, in part, due to a high level of dNTPs which are a consequence of DNA-damage checkpoint activation.

78. Smith CE, Llorente B, Symington LS: Template switching during breakinduced replication. Nature 2007, 447:102-105.

79. Ira G, Haber JE: Characterization of RAD51-independent break-induced replication that acts preferentially with short homologous sequences. Mol Cell Biol 2002, 22:6384-6392.

80. Hastings PJ, Ira G, Lupski JR: A microhomology-mediated break-induced replication model for the origin of human copy number variation. PLoS Genet 2009, 5:e1000327.

*81. Payen C, Koszul R, Dujon B, Fischer G: Segmental duplications arise from Pol32-dependent repair of broken forks through two alternative replication-based mechanisms. PLoS Genet 2008, 4:e1000175.

Duplications of chromosomal segments in yeast are defined by two mechnaisms, NAHR which requires HR pathways and microhomology mediated events which are independent of $H R$

82. Calzada A, Hodgson B, Kanemaki M, Bueno A, Labib K: Molecular anatomy and regulation of a stable replisome at a paused eukaryotic DNA replication fork. Genes \& development 2005, 19:1905-1919.

83. Sofueva S, Osman F, Lorenz A, Steinacher R, Castagnetti S, Ledesma J, Whitby MC: Ultrafine anaphase bridges, broken DNA and illegitimate recombination induced by a replication fork barrier. Nucleic Acids Res 2011, 39:6568-6584.

*84. Dubarry M, Loiodice I, Chen CL, Thermes C, Taddei A: Tight protein-DNA interactions favor gene silencing. Genes Dev 2011, 25:1365-1370.

Together with Refs [90] and [91]: iRFBs (DNA-bound proteins, G4-quadruplex) or global replication stress impact on chromatin structure and gene expression (in yeast, chicken and human cells) establishing that, beyond the maintenance of 
genome stability, impediments to DNA replication potentially jeopardize the inheritance of epigenetic information.

85. Jacome A, Fernandez-Capetillo O: Lac operator repeats generate a traceable fragile site in mammalian cells. EMBO Rep 2011, 12:1032-1038.

**86. Iraqui I, Chekkal Y, Jmari N, Pietrobon V, Fréon K, Costes A, Lambert S:

Recovery of arrested replication forks by homologous recombination is error-prone. PLoS Genet 2012, in press.

A fission yeast replication fork collapsed and restarted at a pRFB induces tumorlike rearrangements including genomic deletions and translocations. This separated the NAHR caused by HR during restart from micro-homology mediated genome modifications due to subsequent inaccurate DNA synthesis by the replisome rebuilt by recombination.

87. Arlt MF, Wilson TE, Glover TW: Replication stress and mechanisms of CNV formation. Curr Opin Genet Dev 2012.

88. Durkin SG, Ragland RL, Arlt MF, Mulle JG, Warren ST, Glover TW:

Replication stress induces tumor-like microdeletions in FHIT/FRA3B. Proc Natl Acad Sci U S A 2008, 105:246-251.

*89. Arlt MF, Ozdemir AC, Birkeland SR, Wilson TE, Glover TW: Hydroxyurea induces de novo copy number variants in human cells. Proc Natl Acad Sci U S A 2011, 108:17360-17365.

Disturbing dNTP supply during S-phase induces de novo CNV characterized by micro-homology at breakpoint junctions. Based on SNP microarrays, a map of $\mathrm{CNV}$ revealed that hot spots of $\mathrm{CNV}$ overlap with genomic deletions previously reported in cancer cell lines.

*90. Jasencakova Z, Scharf AN, Ask K, Corpet A, Imhof A, Almouzni G, Groth A:

Replication stress interferes with histone recycling and predeposition marking of new histones. Mol Cell 2010, 37:736-743.

See annotation to Ref [84]

*91. Sarkies P, Reams C, Simpson LJ, Sale JE: Epigenetic instability due to defective replication of structured DNA. Mol Cell 2010, 40:703-713.

See annotation to Ref [84] 
Box1. Definitions.

Fork-arrest: any circumstance that perturbs the progress of the replisome and the associated replication fork. This can result in a strong slowdown of fork progression.

Fork-stall: fork and replisome remain stably associated, the replisome continues to protect the fork from inappropriate processing and replication can be resumed without further intervention.

Fork-collapse: the replisome is not correctly associated with the fork, the fork and nascent DNA are accessible to DNA processing. Replication cannot resume, but must be restarted with intervention by additional factors (often HR). Broken forks, where there is a double stranded break, can be defined as collapsed forks, but collapsed forks are not necessarily broken.

Resumption: An arrested fork (i.e. stalled) recommences replication without intervention by additional factors

Restart: An arrested fork (i.e. collapsed) recommences replication only after intervention by additional factors (often HR)

HR. Homologous recombination. Genetic exchange between two homologous sequences

BIR. Break induced replication. A singe ended DSB uses HR to invade a homologous sequence via canonical Rad51-mediated strand invasion and initiates the production of a replication fork.

MMBIR. Micro-homology mediated BIR. Similar to BIR, but the invasion only requires a few base-pairs and is independent of Rad51.

MMIR. Similar to MMBIR, but without pre-supposing that the initiating event is a DSB. The initiating event could be a template switch caused by transient dissociation of the nascent strand followed by erroneous re-association with a short region of homology as opposed to the original template. 
Box2. Chromosome rearrangements.

Reciprocal translocation. Simple exchange between homologous sequence transfers chromosome arms.

Non-reciprocal translocation. A recombination event joining two chromosome fragments, but without the reciprocal event. Can occur by BIR for example.

Terminal deletion. Loss of a chromosome fragment, with the broken end healed by telomere addition.

Inverted duplication deletion. Similar to a terminal deletion, but associated with an inverted duplication proximal to the deletion. This could be caused, for example, by generation of a dicentric, which breaks and is subsequently healed by telomere addition.

Inversion. A segment of DNA, usually flanked by repeat sequences or microhomology, is inverted.

Interstitial deletion. A region of DNA is deleted. Often the deleted part was flanked by repeat sequences or microhomology.

Segmental duplication. A region between two homologous sequences or two regions of microhomology is duplicated.

Inverted duplication deletion. An relatively simple example of a complex rearrangement. A region is duplicated and inverted in relation to the original sequence and is associated with a nearby deletion.

Chromothrypsis. An example of a multi-event CR. Multiple exchanges occur between sequences confined to one or a few chromosome regions, but are not associated with increased copy number. One model predicts a chromosome region is broken by DSBs into multiple fragments and randomly joined by nonhomologous end joining. Chromothrypsis has been linked to transient incorporation of chromosome fragments into micronuclei, offering an explanation as to their localised nature. Aberrant replication within the micronuclei could also contribute to chromothrypsis -like events by promoting template switching without DSB intermediates (i.e. MMIR)

Kataegis. Regional hypermutations of base substitutions identified at break point of somatic rearrangements in cancer cells. Kataegis is, in some cases, associated with chromothrypsis. Models addressed in yeast support that kataegis results from cytosine deamination of single stranded DNA stretches as a consequence of replication failures.

Copy number variation or alteration. Gain and losses of genetic material often associated with micro-homology. Natural CNVs occur between individuals and elevated CNVs are a hallmark of cancer cells. 
Table 1. Potential replication fork barriers

\begin{tabular}{|c|c|c|c|}
\hline $\begin{array}{l}\text { Type of replication } \\
\text { hindrances }\end{array}$ & $\begin{array}{l}\text { Impact on } \\
\text { replication fork }\end{array}$ & Mechanisms of rescue & Associated instability \\
\hline $\begin{array}{l}\text { DNA damages: } \\
\text { (bulky adducts, photoproducts, } \\
\text { nicks...) }\end{array}$ & $\begin{array}{l}\text { Stall or breakage, } \\
\text { ssgaps }^{1}\end{array}$ & $\mathrm{PRR}^{2}, \mathrm{TLS}^{3}$ and $\mathrm{HR}^{4}$ & $\begin{array}{l}\text { Single or clustered mutations } \\
\text { (Kataegis) } \\
\text { Associated disease: } \mathrm{XPV}^{5}\end{array}$ \\
\hline \multicolumn{3}{|l|}{ iRFBs linked to DNA metabolism: } & \multirow{4}{*}{$\begin{array}{l}\text { CRs, mutations and template switches } \\
\text { due to error-prone restart by HR }\end{array}$} \\
\hline - DNA bound-proteins & Stall and collapse & specialized helicases, HR & \\
\hline $\begin{array}{l}\text { Interference with active } \\
\text { transcription }\end{array}$ & Stall and collapse & specialized helicases, HR & \\
\hline $\begin{array}{l}\text { - Repressed genes (chromatin } \\
\text { hypo-acetylation) }\end{array}$ & Stall (collapse ?) & specialized helicases, HR & \\
\hline \multicolumn{4}{|l|}{$\begin{array}{l}\text { iRFBs linked to sequence } \\
\text { organization: }\end{array}$} \\
\hline $\begin{array}{l}\text { - Palindromes and inverted } \\
\text { repeats }\end{array}$ & Stall and collapse & specialized helicases, HR & $\begin{array}{c}\text { CRs, acentric and dicentric } \\
\text { Associated disease: sex disorder from } \\
\text { Y chromosome }\end{array}$ \\
\hline - Nucleotide repeats & Stall (collapse ?) & $\begin{array}{c}\text { specialized helicases, MMR, } \\
\text { HR, }\end{array}$ & $\begin{array}{c}\text { Expansions contractions } \\
\text { Associated diseases: fragile } X \\
\text { syndrome, Huntington, Friedreich } \\
\text { Ataxia }\end{array}$ \\
\hline $\begin{array}{l}\text { - Secondary-DNA structure } \\
\text { (AT-rich, non B-form, G4) }\end{array}$ & Stall (collapse ?) & specialized helicases & CRs, deletions \\
\hline Paucity in replication origins & Under-replication & Checkpoint, HR & $\begin{array}{c}\text { Chromosomal breakages, CRs, } \\
\text { deletions, hot spot of integration of } \\
\text { exogenous DNA }\end{array}$ \\
\hline \multicolumn{4}{|l|}{ Global replication stress } \\
\hline - dNTP pool imbalance & Arrest/slow down & Checkpoint, HR? & Non recurrent CNVs (micro-homology) \\
\hline $\begin{array}{l}\text { - Low level of DNA } \\
\text { polymerases }\end{array}$ & Arrest/slow down & Checkpoint, HR? & $\begin{array}{l}\text { Translocations at yeast } \\
\text { retrotransposons } \\
\text { Non recurrent CNVs (micro-homology) }\end{array}$ \\
\hline
\end{tabular}

1: single-stranded DNA gaps

2: Post-Replication Repair

3: Trans-Lesions-Synthesis DNA-polymerases

4: Homologous Recombination

5: Xeroderma-pigmentosum variant. 


\section{Figure legend}

Replication-based mechanisms generating either homology- or micro-homologymediated chromosomal rearrangements, and mutations. (See text for details). 


\section{DNA damages}
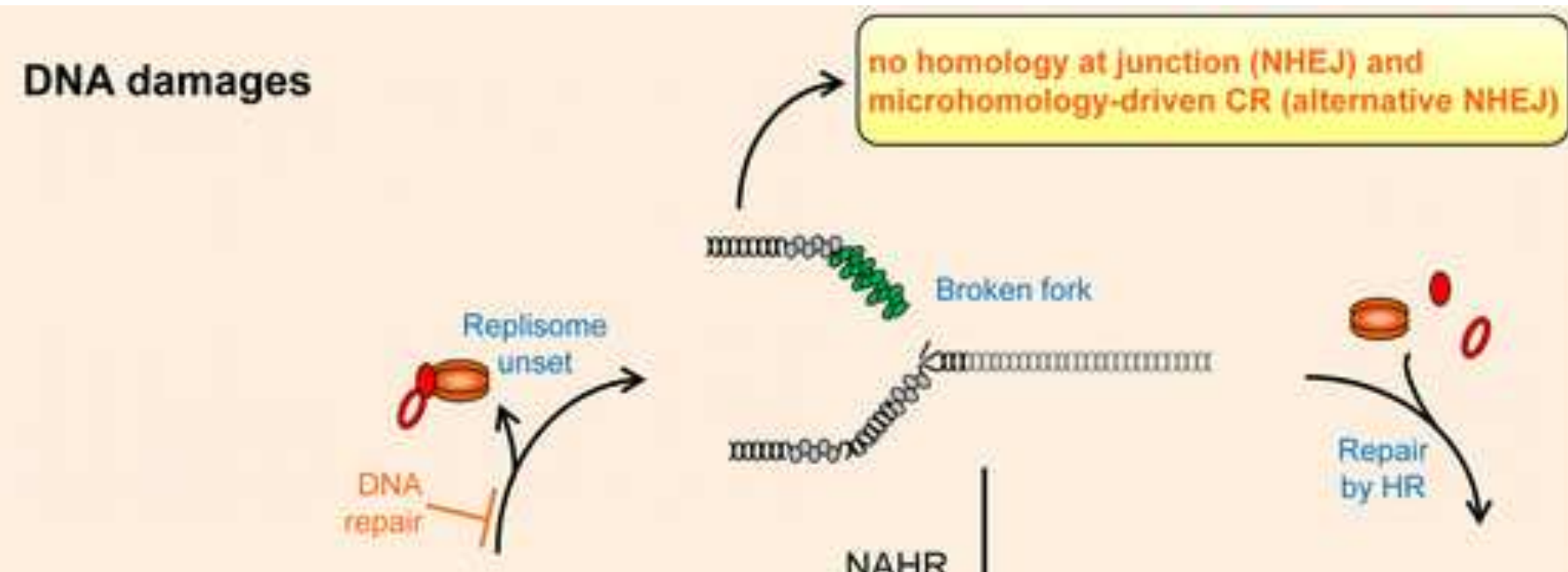

Ori-dependent fork: error-free replisome
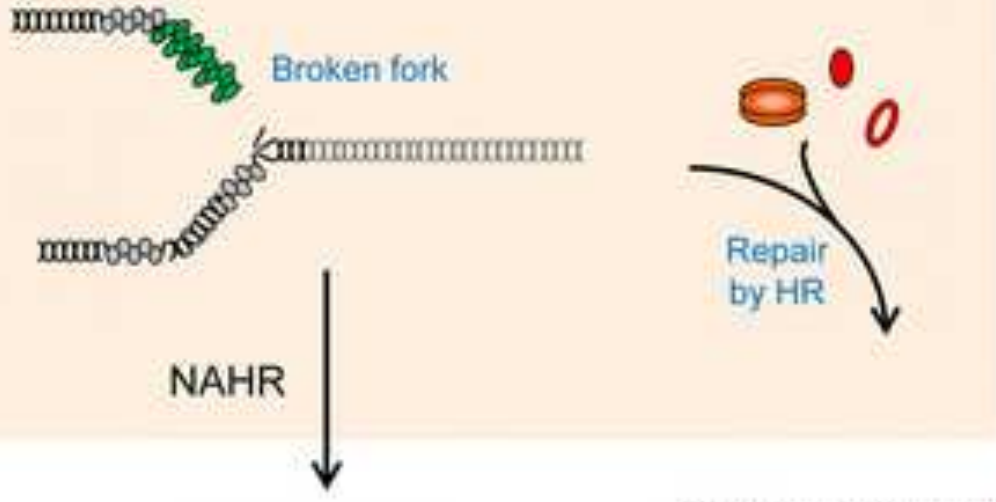

\begin{tabular}{|l} 
Replicative helicase \\
(Cdc45-MCM-GINS) \\
Rad51 Filament \\
Replicative \\
DNA-polymerases \\
0 PCNA \\
000 RPA \\
\hline
\end{tabular}

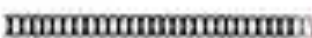

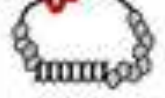
driven CR

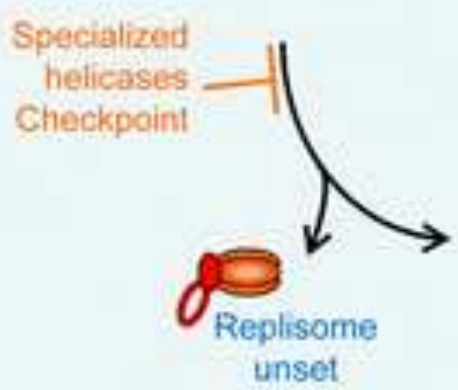

$\sin 0000 x$
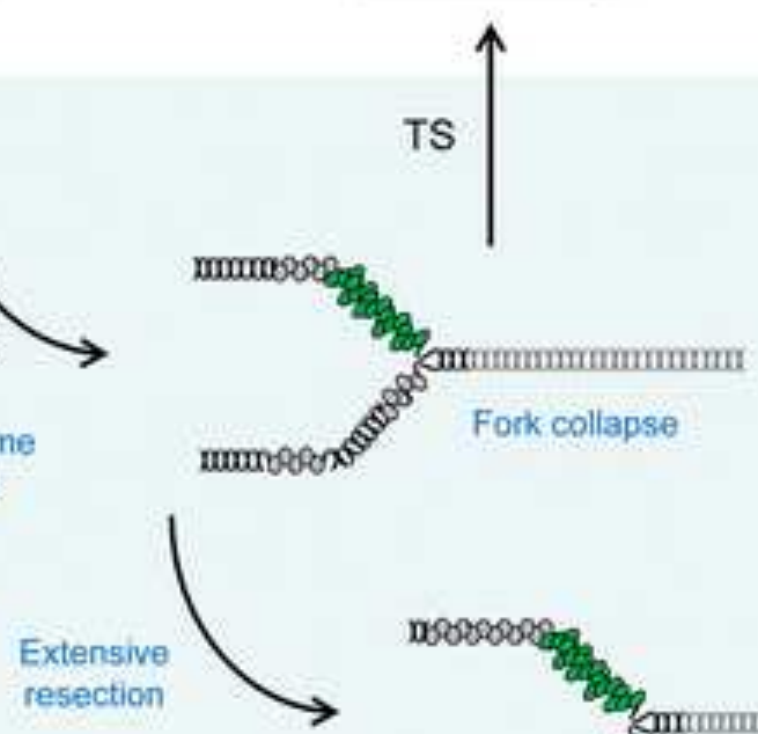

\section{iRFBs}

\section{Global Replication Stress}
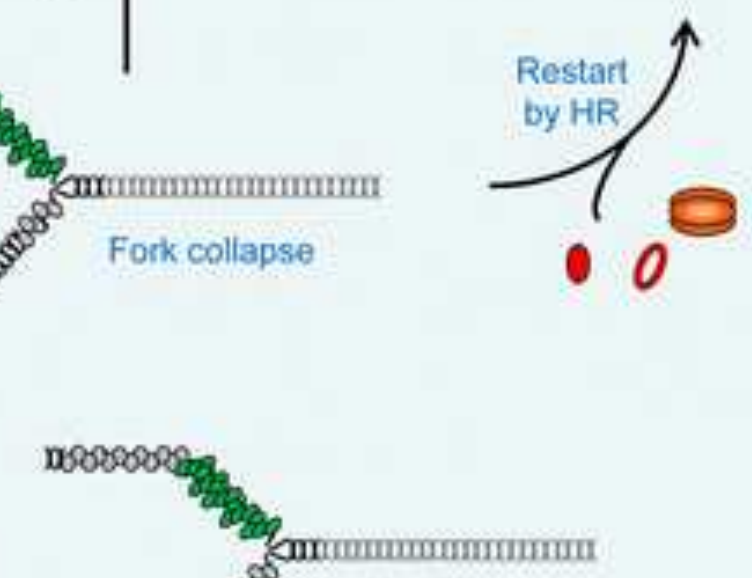

CR: Chromosome Rearrangement

TS: Template Switch

HR: Homologous Recombination

NAHR: Non Allelic Homologous

Recombination

NHEJ: Non Homologous End Joining

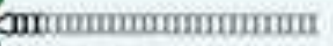

